\title{
Use of the Solid By-Product of Anaerobic Digestion of Biomass to Remove Anthropogenic Organic Pollutants with Endocrine Disruptive Activity
}

\author{
Elisabetta Loffredo*(D), Claudia Carnimeo ${ }^{(D)}$, Roccangelo Silletti and Carmine Summo \\ Dipartimento di Scienze del Suolo, della Pianta e degli Alimenti, Università degli Studi di Bari Aldo Moro, \\ 70126 Bari, Italy; claudia.carnimeo@uniba.it (C.C.); roccangelo.silletti@uniba.it (R.S.); \\ carmine.summo@uniba.it (C.S.) \\ * Correspondence: elisabetta.loffredo@uniba.it; Tel.: +39-080-5442282
}

\section{check for} updates

Citation: Loffredo, E.; Carnimeo, C.; Silletti, R.; Summo, C. Use of the Solid By-Product of Anaerobic Digestion of Biomass to Remove Anthropogenic Organic Pollutants with Endocrine Disruptive Activity. Processes 2021, 9, 2018. https://doi.org/10.3390/ pr9112018

Academic Editors: Andrea Petrella, Marco Race and Danilo Spasiano

Received: 26 September 2021

Accepted: 9 November 2021

Published: 11 November 2021

Publisher's Note: MDPI stays neutral with regard to jurisdictional claims in published maps and institutional affiliations.

Copyright: (c) 2021 by the authors. Licensee MDPI, Basel, Switzerland. This article is an open access article distributed under the terms and conditions of the Creative Commons Attribution (CC BY) license (https:/ / creativecommons.org/licenses/by/ $4.0 /$ )
Abstract: Anaerobic digestion of biomass has increasing implementation for bioenergy production. The solid by-product of this technology, i.e., the digestate, has relevant potential in agricultural and environmental applications. This study explored the capacity of a digestate from mixed feedstock to remove from water four endocrine-disrupting chemicals, namely the pesticides metribuzin (MET) and boscalid (BOS) and the xenoestrogens bisphenol A (BPA) and 4-tert-octylphenol (OP). The surface micromorphology and functional groups of the digestate were investigated using scanning electron microscopy (SEM) and Fourier-transform infrared (FTIR) spectroscopy, respectively. Results of sorption kinetics showed that all compounds reached the steady state in a few hours according to a pseudo-first-order model in the cases of MET and OP, a pseudo-second-order model for BOS and both models in the case of BPA. Data of adsorption isotherms were fitted to the Henry, Freundlich, Langmuir and Temkin equations. The adsorption of MET preferentially followed the non-linear Freundlich model, whereas the adsorption of the other compounds was properly described by both the linear and Freundlich models. The organic carbon partition coefficients, $\mathrm{K}_{\mathrm{OC}}$, were 170, 1066, 256 and $2180 \mathrm{~L} \mathrm{~kg}^{-1}$ for MET, BOS, BPA and OP, respectively. The desorption of BOS, BPA and OP was slow and incomplete, indicating a phenomenon of hysteresis. In conclusion, the digestate showed a remarkable efficiency in the removal of the compounds, especially those with high hydrophobicity, thus behaving as a promising biosorbent for environmental remediation.

Keywords: digestate; endocrine-disrupting chemical; metribuzin; boscalid; bisphenol A; octylphenol; xenoestrogen; sorption kinetics; sorption isotherm; desorption

\section{Introduction}

The current practice of processing waste biomass to produce bioenergy is increasingly adopted all over the world, representing a virtuous alternative to the consumption of fossil fuels. This approach can effectively cope with more than one emergency, such as the ever-increasing global demand for energy, the need to dispose of the huge mass of solid and liquid organic wastes from agro-zootechnical, industrial and urban activities and the need to implement a circular economy.

Several traditional and innovative conversion technologies, such as pyrolysis, microgasification, hydrothermal carbonization and anaerobic digestion (AD), have been developed by scientists and specialists to obtain combustible biogas and biofuels from organic wastes or dedicated crops [1]. These processes can also be combined to improve bioenergy production and usable remains [2,3]. The resulting by-products from these technologies are carbon-rich materials suitable for agricultural and environmental applications [4]. In agricultural practice, these materials can be used to improve soil fertility, as they are able to compensate for the widespread progressive decline of soil organic matter and also act as modulators of the bioavailability of phytonutrients and contaminants [5]. In environmental 
remediation strategies, these by-products can be exploited as biosorbents of various types of pollutants [4].

The AD process is a biological conversion of plant and animal wastes operated by various bacterial and archaeal populations [6]. Starting from different organic feedstocks, AD produces biogas and a concentrated semi-solid organic/inorganic mixture that, after a separation phase, gives a solid digestate (DIG) and a separate clarified liquid also called liquid digestate [3]. The chemical and physical properties of the DIG depend on the type of biomass used and the production parameters adopted and significantly influence the best utilization of the DIG [7]. During the AD process, the easily degradable organic compounds are readily converted into biogas, while the remaining more recalcitrant lignocellulosic components have remarkable retention properties towards inorganic and organic compounds. Some properties of DIG, such as surface reactive functional groups, a microstructure with some porosity and a large surface area, make this material a good biosorbent for organic compounds. Recently, DIG has been used successfully in mixtures with other carbon-rich substrates to prepare biofilters and biobeds [8].

Practices of conventional agriculture, such as the use of agrochemicals and the application to the soil of wastewater and sewage sludge not thoroughly decontaminated, have contributed to the release into the environment of anthropogenic organic pollutants (AOPs). AOPs include different classes of compounds, such as synthetic biocides, dyes, pharmaceuticals, personal care products, surfactants, wood preservatives and industrial products and by-products [9]. Many AOPs are biopersistent pollutants, and several of them have been recognized as endocrine-disrupting chemicals (EDCs) $[10,11]$. Even at very low levels, EDCs are capable of altering the normal hormonal functionality of humans and animals, especially aquatic animals, causing a variety of health effects, such as dysfunctions and pathologies of the reproductive apparatus and the cardiovascular system [12,13].

Among the AOPs with EDC activity, there are many plant protection products used intensively around the world to control crop diseases and ensure food production. Inappropriate and repeated use of these compounds can exceed the self-depollution capacity of the soil and accumulate in plants, soil and natural waters, with high risk for humans and ecosystems [14]. Metribuzin (4-amino-6-tert-butyl-3-(methylsulfanyl)-1,2,4-triazin-5(4H)on) (MET) is a triazinone herbicide widely used to control broadleaf weeds in various crops. Due to its high water solubility, MET is considered to be one of the pesticides with the greatest potential for moving to surface and groundwater [15]. Another largely used pesticide is boscalid (2-chloro-N-(4'-chlorobiphenyl-2-yl)-nicotinamide) (BOS), which is a broad-spectrum carboxamide fungicide applied to protect fruit and horticultural plants. BOS is persistent in soil and especially in aquatic systems [16]. Recently, the European Commission has included both MET and BOS in the list of suspected EDCs [10].

Well-known EDCs are the xenoestrogens bisphenol A (2,2-Bis(4-hydroxyphenyl) propane) (BPA) and 4-tert-octylphenol (OP). BPA is widely used for the industrial production of polycarbonate and epoxy resins, flame retardants, food and beverage packaging, bottle caps and water supply systems [17]. The OP molecule is generated by the microbial degradation of octylphenol polyethoxylates which are non-ionic surfactants used in the production of paints, detergents and pesticides [18]. OP is largely present in the effluents of sewage sludge treatment plants and is biopersistent in the environment due to recalcitrance [18]. All these compounds can be detected in soil and natural waters where they pose serious environmental problems and health risks $[19,20]$.

New sustainable strategies for removing EDCs from environmental matrices have recently been explored, including adsorption techniques using low-cost carbon-rich adsorbents obtained from processed biowaste, such as DIG. The sorption process consists of the accumulation of an adsorbate at the interface between the adsorbent phase and the solution phase. It is favourably regarded by researchers and operators for its easy-to-make features, low energy consumption and considerable efficiency.

In soil, the organic components, in particular the humic fraction, play a prominent role in the retention of pollutants. The low level of organic matter in some soils can therefore 
seriously compromise the self-depollution capacity of the soil and, consequently, the quality and fertility of the soil. Furthermore, the adsorption/desorption process controls the entire dynamic of contaminants in the soil-plant system, including movement and persistence. Therefore, the addition to the soil of organic amendments, such as DIG, can replace, at least in part, the native organic matter, with multiple benefits for the environment. The sorption of pollutants on DIG can prevent the leaching of these compounds, especially the more polar ones and control their bioavailability for plants and microorganisms. This is extremely important in the case of biopersistent molecules [21]. The removal of contaminants from water and wastewater is also very important. However, the use of expensive synthetic adsorbents, such as commercial activated carbon, and sophisticated technologies have become environmentally and economically unsustainable. Therefore, recent research has focused on the possible exploitation of biosorbents from biomass recycling and by-products of bioenergy production $[4,22]$.

The interaction between pesticides and/or EDCs and carbon-rich materials has been extensively studied $[8,23,24]$. However, most studies concern the adsorption of individual AOPs on biosorbents such as compost and biochar [25-28], while little information exists on the use of DIG to remove AOPs [8]. Furthermore, few studies have evaluated the removal of AOPs from multi-contaminated matrices [29]. In real environmental systems, such as soil, contaminants with different properties and hydrophobicity coexist and interact simultaneously with solid and dissolved components, especially organic ones. The same happens in wastewater which is usually contaminated with many types of inorganic and organic compounds. Considering all this, the objective of this study was to investigate the quantitative aspects of the adsorption/desorption process of four EDCs with contrasting physicochemical properties, namely MET, BOS, BPA and OP, on a DIG sample obtained from a mixed plant and animal biomass.

\section{Materials and Methods}

\subsection{Chemicals and Digestate}

Metribuzin (MET) at a purity of $\geq 98.0 \%$, boscalid (BOS) at $99.0 \%$ purity, bisphenol A (BPA) at $99.0 \%$ purity and 4-tert-octylphenol (OP) at $99.5 \%$ purity were purchased from Sigma-Aldrich S.r.l., Milano, Italy. Structural formula and some chemical properties of the compounds are reported in Table 1. All other chemicals of extra pure grade were obtained from commercial sources and used without further purification. Aqueous mixtures of MET, BOS, BPA and OP were prepared by diluting appropriate aliquots of individual methanol (HPLC grade) solutions of the compounds at a concentration of $2000 \mathrm{mg} \mathrm{L}^{-1}$ with double-distilled water. At the maximum concentration of the compounds used in the experiments $\left(2 \mathrm{mg} \mathrm{L}^{-1}\right)$, the percentage of methanol in the final mixture was $0.4 \%$.

The digestate (DIG) sample was obtained through anaerobic digestion from a mixture of oat silage, manure, slurry, cereal by-products, and two-phase olive pomace. The DIG sample was provided by F.lli Caione Azienda Agricola La Quercia Soc. Coop., Foggia, Italy. Before use, the DIG was air-dried and then characterized according to conventional methods. Some characteristics of air-dried DIG are reported in Table 2.

\subsection{Scanning Electron Microscopy Analysis}

Scanning electron microscopy (SEM) analysis of the DIG was performed to evaluate the surface micromorphology. The sample was fixed with an adhesive carbon tape, metallized with graphite, and analyzed with a high-resolution field emission scanning electron microscope VP FE-SEM $\Sigma$ IGMA 300 (ZEISS, Oberkochen, Germany) equipped with an energy dispersive X-ray (EDX) elemental analyzer. The SEM micrographs of the DIG were captured at both $2500 \times$ and $13,000 \times$ magnifications using a $5 \mathrm{kV}$ acceleration potential. 
Table 1. Some properties of the compounds.

\begin{tabular}{|c|c|c|c|c|}
\hline Compound & $\begin{array}{l}\text { Chemical } \\
\text { Structure }\end{array}$ & $\begin{array}{c}\text { Molecular } \\
\text { Weight (g/mol) }\end{array}$ & $\begin{array}{l}\text { Water Solubility } \\
\quad\left(\mathrm{mg} \mathrm{L}^{-1}\right)\end{array}$ & Log Kow \\
\hline Metribuzin & & 214.29 & 1200 & 1.70 \\
\hline Boscalid & & 343.21 & 4.6 & 2.96 \\
\hline Bisphenol A & & 228.29 & 300 & 3.32 \\
\hline $\begin{array}{c}\text { 4-tert- } \\
\text { octylphenol }\end{array}$ & & 206.32 & 3.1 & 5.50 \\
\hline
\end{tabular}

Table 2. Some properties of the air-dried digestate.

\begin{tabular}{|c|c|}
\hline Parameter & Value \\
\hline $\mathrm{pH}^{\mathrm{a}}$ & $8.73 \pm 0.08^{b}$ \\
\hline $\mathrm{EC}\left(\mathrm{dS} \mathrm{m}^{-1}\right)^{\mathrm{a}}$ & $1.36 \pm 0.04$ \\
\hline Dry matter (\%) & $87.41 \pm 0.63$ \\
\hline Volatile solids (\% d.m.) & $87.15 \pm 0.47$ \\
\hline Total organic carbon (\% d.m.) & $50.55 \pm 0.27$ \\
\hline Ash (\% d.m) & $12.85 \pm 0.54$ \\
\hline
\end{tabular}

${ }^{\mathrm{a}} \mathrm{DIG} / \mathrm{H}_{2} \mathrm{O}, 1: 10 w / v .{ }^{\mathrm{b}}$ All values are the mean $\pm \mathrm{SD}(\mathrm{n}=3)$.

\subsection{Fourier-Transform Infrared Analysis}

Fourier-transform infrared (FTIR) analyses were performed to investigate the surface functional groups of the DIG sample before and after the 24-h interaction with an aqueous solution of the four compounds at the individual concentration of $2 \mathrm{mg} \mathrm{L}^{-1}$. A mixture of $2 \mathrm{mg}$ of dried DIG (before and after interaction) and $400 \mathrm{mg}$ of dried $\mathrm{KBr}$ (FTIR grade) was homogenized using an agate mortar and pestle. A pellet was obtained from the mixture by pressing under vacuum at a pressure of $6000 \mathrm{~kg} \mathrm{~cm}^{-1}$ for $10 \mathrm{~min}$. Fourier-transform infrared (FTIR) spectra were recorded using a Thermo Nicolet iS50 FTIR spectrophotometer in the range $4000-400 \mathrm{~cm}^{-1}$ with a resolution of $2 \mathrm{~cm}^{-1}$ and $16 \mathrm{scans} \mathrm{min}^{-1}$ for each acquisition.

\subsection{Preliminary Adsorption Experiments}

Preliminary adsorption experiments were conducted in batch mode to evaluate the efficiency of different solution/DIG ratios in removing the compounds. For the purpose, aliquots of 40,50, 100 and $200 \mathrm{mg}$ of DIG were made to interact with a volume of $20 \mathrm{~mL}$ of a mixture of MET, BOS, BPA and OP at the individual concentration of $2 \mathrm{mg} \mathrm{L}^{-1}$, thus obtaining solution/substrate ratios equal to 500, 400, 200 and 100. All samples were mechanically shaken at $350 \times g$ for $24 \mathrm{~h}$ at a temperature of $20 \pm 1{ }^{\circ} \mathrm{C}$ to reach sorption equilibrium. Previous experiments showed that, for each compound, no further adsorption occurred after $24 \mathrm{~h}$. Successively, the suspensions were centrifuged at $10,000 \times g$ for $10 \mathrm{~min}$. A volume of $18 \mathrm{~mL}$ of supernatant solution was collected from each sample and the equilibrium concentration of each compound was measured by high performance liquid chromatography (HPLC) as described in Section 2.6. All experiments were triplicated. The 
amount of compound sorbed on the DIG unit after $24 \mathrm{~h}, \mathrm{q}_{\mathrm{t}}\left(\mathrm{mg} \mathrm{kg}^{-1}\right)$, was calculated from the equation:

$$
\mathrm{q}_{\mathrm{t}}=\left(\mathrm{C}_{0}-\mathrm{C}_{\mathrm{t}}\right) \mathrm{V} / \mathrm{m}
$$

where $\mathrm{C}_{0}\left(\mathrm{mg} \mathrm{L}^{-1}\right)$ is the initial concentration of the compound in solution, $\mathrm{C}_{\mathrm{t}}\left(\mathrm{mg} \mathrm{L}^{-1}\right)$ is the concentration of the compound at time $t(24 \mathrm{~h}$ in these experiments), $\mathrm{V}(\mathrm{L})$ is the volume of the solution and $\mathrm{m}(\mathrm{kg})$ is the mass of the substrate.

The experimental sorption data for each compound (triplicated values) were statistically analyzed using one-way analysis of variance (ANOVA) followed by the Duncan's new multiple range test at $P \leq 0.01$.

\subsection{Adsorption and Desorption Experiments}

Sorption kinetics were performed to evaluate the adsorption rates of MET, BOS, BPA and OP onto the DIG sample and to establish the time required to reach equilibrium. Based on the results obtained from the preliminary trials, in the subsequent experiments, a solution/substrate ratio of 500 was adopted, that is the ratio that allowed the maximum adsorption efficiency of the DIG. Hence, volumes of $10 \mathrm{~mL}$ of an aqueous mixture of the four compounds at individual concentration of $2 \mathrm{mg} \mathrm{L}^{-1}$ and $\mathrm{pH}$ of 8.09 were added to $20 \mathrm{mg}$ of DIG in glass centrifuge tubes. The suspensions were then stirred for $0.25,0.5,1,4$, 8,16 and $24 \mathrm{~h}$ in the dark at $20 \pm 1^{\circ} \mathrm{C}$. After each time, the suspensions were centrifuged at $10,000 \times g$ for $10 \mathrm{~min}$ and the supernatants were analyzed by HPLC to determine the residual concentration of each compound in solution (see Section 2.6). All experiments were triplicated. The amount of compound sorbed on the substrate unit at each time $t$, $\mathrm{q}_{\mathrm{t}}\left(\mathrm{mg} \mathrm{kg}^{-1}\right)$ was calculated from Equation (1). To determine the sorption equilibrium time, the Student's $t$-test was used to compare, two-by-two, the quantities of compound adsorbed at any time $(P \leq 0.05)$. The equilibrium time was established when there was no significant difference between the values at two successive times. Then, ANOVA and the Duncan's new multiple range test $(P \leq 0.01)$ were performed to evaluate significant differences among the adsorbed quantities at equilibrium.

Adsorption isotherms of the four compounds onto the DIG were performed using the batch equilibration method. Aliquots of $20 \mathrm{mg}$ of DIG were added with $10 \mathrm{~mL}$ of aqueous mixtures of MET, BOS, BPA and OP at individual concentrations of $0.2,0.4,0.5$, 1 and $2 \mathrm{mg} \mathrm{L}^{-1}$ in glass centrifuge tubes. Based on the adsorption kinetics results, the suspensions were stirred for $24 \mathrm{~h}$ at $20 \pm 1{ }^{\circ} \mathrm{C}$ in the dark to reach equilibrium. Then, the suspensions were centrifuged at $10,000 \times g$ for $10 \mathrm{~min}$ and the equilibrium concentration of each compound in the supernatants was measured by HPLC (see Section 2.6). All experiments were triplicated.

Desorption experiments were started immediately after adsorption using the DIG sample added with the maximum initial concentration of each compound $\left(2 \mathrm{mg} \mathrm{L}{ }^{-1}\right)$. For all four desorption cycles, an aliquot of $8 \mathrm{~mL}$ of equilibrium supernatant solution was replaced with the same volume of distilled water. The sample was stirred again for $24 \mathrm{~h}$ at $20 \pm 1^{\circ} \mathrm{C}$ and centrifuged in the conditions reported above. Then, the supernatant solution was collected, and the compounds were analyzed using the HPLC procedure described in the next section.

\subsection{Chromatographic Analysis}

The concentration of each compound in solution was measured using an HPLC apparatus equipped with a Spectra System ${ }^{\mathrm{TM}}$ pump (Thermo Electron Corporation, San Jose, CA, USA), a Rheodyne ${ }^{\circledR} 7125$ injector with a $20 \mu \mathrm{L}$ loop and a Supelcosil ${ }^{\mathrm{TM}}$ LC-18 chromatographic column $(250 \mathrm{~mm} \times 4.6 \mathrm{~mm} \times 5 \mu \mathrm{m})$. The mobile phase was a mixture of water (A) and acetonitrile (B) flowing at $0.8 \mathrm{~mL} \mathrm{~min}^{-1}$. The gradient elution adopted was: $0-4 \mathrm{~min}, 50 \% \mathrm{~B}$; 4-8 $\mathrm{min}$, from 50 to $70 \% \mathrm{~B} ; 8-15 \mathrm{~min}$, from 70 to $90 \% \mathrm{~B}$. Retention times of MET, BOS, BPA and OP were 4.0, 6.2, 9.2 and $13.6 \mathrm{~min}$, respectively. MET and BOS were detected using a Spectra System UV6000LP ${ }^{\mathrm{TM}}$ diode array detector at wavelengths of $294 \mathrm{~nm}$ and $207 \mathrm{~nm}$, respectively. BPA and OP were quantified by a Spectra System FL3000 
fluorescence detector operating at wavelengths of 240-nm excitation and 310-nm emission. All compounds were quantified using the external standard method.

\subsection{Sorption and Desorption Models}

Two theoretical models were used to interpret the sorption kinetics data, determine the kinetic constants and investigate the sorption mechanisms of the compounds onto the DIG. The pseudo-first-order model of Lagergren [31] is based on sorbent capacity. The non-linear form of the pseudo-first-order kinetic model is given by the equation [32]:

$$
\mathrm{q}_{\mathrm{t}}=\mathrm{q}_{\mathrm{e}}\left(1-\exp ^{-\mathrm{k} 1 \mathrm{t}}\right)
$$

where $\mathrm{q}_{\mathrm{e}}$ and $\mathrm{q}_{\mathrm{t}}$ are the amount of the compound adsorbed per mass unit of adsorbent $\left(\mathrm{mg} \mathrm{kg}^{-1}\right)$ at equilibrium and at time $\mathrm{t}$, respectively, and $\mathrm{k}_{1}\left(\mathrm{~h}^{-1}\right)$ is the rate constant of the pseudo-first-order kinetics. The non-linearized form of the pseudo-second-order kinetic model, based on equilibrium sorption, is expressed as [33]:

$$
\mathrm{q}_{\mathrm{t}}=\frac{\mathrm{q}_{\mathrm{e}}^{2} \mathrm{k}_{2} \mathrm{t}}{1+\mathrm{k}_{2} \mathrm{q}_{\mathrm{e}} \mathrm{t}}
$$

In this equation, $\mathrm{q}_{\mathrm{t}}$ and $\mathrm{q}_{\mathrm{e}}$ have already been described for the previous model and $\mathrm{k}_{2}\left(\mathrm{~kg} \mathrm{mg}^{-1} \mathrm{~h}^{-1}\right)$ is the second-order adsorption rate constant. Then, using the solver add-in component of Microsoft Excel, a trial-and-error procedure was adopted to estimate the pseudo-first-order and pseudo-second-order kinetic parameters with the non-linear regression method [33]. To quantify the fit of the two equations to the experimental data, the widely used error function coefficient of correlation, $r$, was adopted:

$$
r=\sqrt{\frac{\sum\left(\mathrm{q}_{\mathrm{t}} \mathrm{m}-\overline{\mathrm{q}_{\mathrm{t}}}\right)^{2}}{\sum\left(\mathrm{q}_{\mathrm{t}} \mathrm{m}-\overline{\mathrm{q}_{\mathrm{t}}}\right)^{2}+\sum\left(\mathrm{q}_{\mathrm{t}} \mathrm{m}-\mathrm{q}_{\mathrm{t}}\right)^{2}}}
$$

where $\mathrm{q}_{\mathrm{t}} \mathrm{m}$ is the amount of solute adsorbed per mass unit of sorbent $\left(\mathrm{mg} \mathrm{kg}^{-1}\right)$ at time $\mathrm{t}$ according to the kinetic model considered, $\mathrm{q}_{\mathrm{t}}$ is the experimental amount of solute adsorbed per mass unit of sorbent $\left(\mathrm{mg} \mathrm{kg}^{-1}\right)$ and $\overline{\mathrm{q}_{\mathrm{t}}}$ is the mean of $\mathrm{q}_{\mathrm{t}}\left(\mathrm{mg} \mathrm{kg}^{-1}\right)$.

The adsorption isotherms data for each compound were interpreted with four sorption models, the two-parameter non-linear empirical equations of Freundlich, Langmuir and Temkin and the linear Henry equation. The Freundlich isotherm model assumes a multilayer adsorption of the sorbate on the substrate and is described by the equation:

$$
\mathrm{q}_{\mathrm{e}}=\mathrm{K}_{\mathrm{F}} \mathrm{C}_{\mathrm{e}}^{1 / \mathrm{n}}
$$

where $\mathrm{q}_{\mathrm{e}}\left(\mathrm{mg} \mathrm{kg}^{-1}\right)$ is the amount of compound adsorbed per unit of substrate, $\mathrm{C}_{\mathrm{e}}\left(\mathrm{mg} \mathrm{L}^{-1}\right)$ is the equilibrium concentration of the sorbate in solution, $1 / \mathrm{n}$ indicates the degree of nonlinearity between the concentration of the compound in solution and that adsorbed, the reciprocal $\mathrm{n}$ expresses the sorption intensity and $\mathrm{K}_{\mathrm{F}}$ (better indicated as $\mathrm{K}_{\mathrm{F} \text {-ads }}$ and $\mathrm{K}_{\mathrm{F} \text {-des }}$ for adsorption and desorption, respectively) is the measure of the sorption capacity of the adsorbent. The Langmuir model is based on a monolayer adsorption and is expressed by:

$$
\mathrm{q}_{\mathrm{e}}=\left(\mathrm{K}_{\mathrm{L}} \mathrm{C}_{\mathrm{e}} \mathrm{b}\right) /\left(1+\mathrm{K}_{\mathrm{L}} \mathrm{C}_{\mathrm{e}}\right)
$$

where $\mathrm{q}_{\mathrm{e}}$ and $\mathrm{C}_{\mathrm{e}}$ are defined as in Equation (5), $\mathrm{b}\left(\mathrm{mg} \mathrm{kg}^{-1}\right)$ is the maximum adsorption capacity of the adsorbent, i.e., the amount of compound forming a monolayer on the adsorbent and $\mathrm{K}_{\mathrm{L}}\left(\mathrm{L} \mathrm{mg}^{-1}\right)$ is the Langmuir constant that expresses the energy of adsorption, that is the affinity between the adsorbent and the sorbate. The Temkin isotherm predicts a logarithmic reduction of adsorptive site and energy and is expressed by:

$$
\mathrm{q}_{\mathrm{e}}=\mathrm{B} \ln \left(\mathrm{A}_{\mathrm{T}} \mathrm{C}_{\mathrm{e}}\right)
$$


where $q_{e}$ and $C_{e}$ have the same meaning as the previous Equations (5) and (6), $A_{T}$ is the Temkin isotherm equilibrium binding constant $\left(\mathrm{L} \mathrm{mg}^{-1}\right)$ and $\mathrm{B}\left(\mathrm{J} \mathrm{mol}^{-1}\right)$ is a parameter expressing the enthalpy of the adsorption. In this equation, $B=R T / b_{T}$, where $b_{T}$ is $a$ constant related to the heat of adsorption, $\mathrm{T}$ is the absolute temperature $(\mathrm{K})$ and $\mathrm{R}$ is the universal gas constant $\left(8.314 \mathrm{~J} \mathrm{~mol}^{-1} \mathrm{~K}^{-1}\right)$. The adsorption parameters $\mathrm{K}_{\mathrm{F}}$ and $1 / \mathrm{n}$ of the Freundlich equation (Equation (5)), $b$ and $K_{L}$ of the Langmuir equation (Equation (6)) and $\mathrm{B}$ and $\mathrm{A}_{\mathrm{T}}$ of the Temkin equation (Equation (7)) were estimated through the non-linear regression method using the solver add-in component of Microsoft Excel and a trial-anderror procedure which minimized the sum of squared residuals (SSR) between observed and simulated concentrations [8]. The fit of the three equations to the experimental data was quantified using the error function coefficient of correlation, r, as described for the calculation of the kinetic parameters (Equation (4)).

Finally, the Henry linear equation:

$$
\mathrm{qe}_{\mathrm{e}}=\mathrm{K}_{\mathrm{d}} \mathrm{C}_{\mathrm{e}}
$$

assumes a constant proportion between the concentration of the sorbate in solution and the concentration of the sorbate on the adsorbent over the concentration range studied. Equation (7) allowed the calculation of the distribution coefficient, $\mathrm{K}_{\mathrm{d}}\left(\mathrm{L} \mathrm{kg}^{-1}\right)$, from the slope. The amount of adsorbed compound per unit of organic $\mathrm{C}$ (OC) of substrate, i.e., the organic-carbon-partition coefficient $\mathrm{K}_{\mathrm{OC}}$, was also calculated according to: $\mathrm{K}_{\mathrm{OC}}=\left(\mathrm{K}_{\mathrm{d}} \times\right.$ 100)/(\%OC)) [23].

Using the same calculation procedure adopted to obtain the sorption parameters, the desorption data, i.e., the quantity of each compound remained adsorbed at each desorption step and the corresponding equilibrium concentration, were fitted in the Freundlich equation to calculate the parameters $\mathrm{K}_{\mathrm{F} \text {-des }}$ and $1 / \mathrm{n}_{\mathrm{des}}$ and in the Henry equation to calculate $\mathrm{K}_{\mathrm{d} \text {-des }}$ and $\mathrm{K}_{\mathrm{OC} \text {-des }}$. Finally, the hysteresis coefficient, $\mathrm{H}$, for the adsorption-desorption isotherm was calculated from the ratio $H=\left(1 / n_{\text {des }}\right) /\left(1 / n_{\text {ads }}\right)$ [34]. In general, a $H$ value $<1$ is indicative of a hysteretic condition, i.e., difficulty for the sorbate to be desorbed from the substrate.

\section{Results and Discussion}

\subsection{SEM Analysis}

The SEM technique identifies the micromorphological aspects of the material surface with information on the distribution and allocation of the pores. The surface features of the DIG sample were evaluated using SEM coupled with an EDX elemental analyzer. Images obtained at $2500 \times$ and $13,000 \times$ magnifications are shown in Figure 1 . The surface of the DIG sample appeared rough and presented numerous irregularly shaped ridges, sharp edges, microparticles, channels and cavities of mostly less than $10 \mu \mathrm{m}$ (Figure 1). The pores, which generally originate from cell walls and vascular tissues, were not so evident. Porosity and a large surface area are extremely important properties when the material is used as an adsorbent for decontamination purposes. The EDX spectrum obtained for the DIG sample evidenced the presence on the surface of various elements typical of plant-based materials (Figure 1).

\subsection{FTIR Analysis}

The surface functional groups of the DIG and their modification after adsorption of the four compounds were investigated using Fourier-transform infrared (FTIR) spectroscopy (Figure 2). The main features of the FTIR spectrum of the DIG were the following: (a) a strong band centered at $3410 \mathrm{~cm}^{-1}$, typical of $\mathrm{O}-\mathrm{H}$ and $\mathrm{N}-\mathrm{H}$ stretching, also hydrogen bonded; (b) two twin peaks of medium intensity at 2925 and $2853 \mathrm{~cm}^{-1}$ attributable to aliphatic C-H stretching; (c) a medium-strong peak at $1638 \mathrm{~cm}^{-1}$ with a shoulder at $1598 \mathrm{~cm}^{-1}$ that can be ascribed to various vibrations, including aromatic $\mathrm{C}=\mathrm{C}$ stretching, $\mathrm{C}=\mathrm{O}$ stretching of amide groups (amide $\mathrm{I}$ band) and ketonic $\mathrm{C}=\mathrm{O}$ and $\mathrm{COO}^{-}$symmetric stretching; (d) a weak peak at $1510 \mathrm{~cm}^{-1}$ feasibly due to aromatic $\mathrm{C}=\mathrm{C}$ stretching and $\mathrm{N}-\mathrm{H}$ 
deformation and $\mathrm{C}=\mathrm{N}$ stretching of amide groups (amide II band); (e) two weak peaks at 1456 and $1423 \mathrm{~cm}^{-1}$ possibly due to aliphatic $\mathrm{C}-\mathrm{H}$ deformation; (f) an intense peak at $1385 \mathrm{~cm}^{-1}$ that can be attributed to various vibrations, including $\mathrm{O}-\mathrm{H}$ deformation and $\mathrm{C}-\mathrm{O}$ stretching of phenolic groups, $\mathrm{C}-\mathrm{H}$ deformation of $\mathrm{CH}_{2}$ and $\mathrm{CH}_{3}$ groups and $\mathrm{COO}^{-}$ asymmetric stretching; $(\mathrm{g})$ a weak peak with a shoulder at $1230 \mathrm{~cm}^{-1}$ possibly due to $\mathrm{C}-\mathrm{O}$ stretching, $\mathrm{O}-\mathrm{H}$ deformation of $\mathrm{COOH}$ and $\mathrm{C}-\mathrm{O}$ stretching of aryl ethers and phenols; (h) a shoulder at $1153 \mathrm{~cm}^{-1}$ attributable to aliphatic $\mathrm{C}-\mathrm{OH}$ stretching; (i) a medium-strong band at $1040 \mathrm{~cm}^{-1}$ with a shoulder at $1107 \mathrm{~cm}^{-1}$ typical of $\mathrm{C}-\mathrm{O}$ stretching of polysaccharide-like substances and $\mathrm{Si}-\mathrm{O}$ silicate impurities in the digestate (Figure 2) [23].
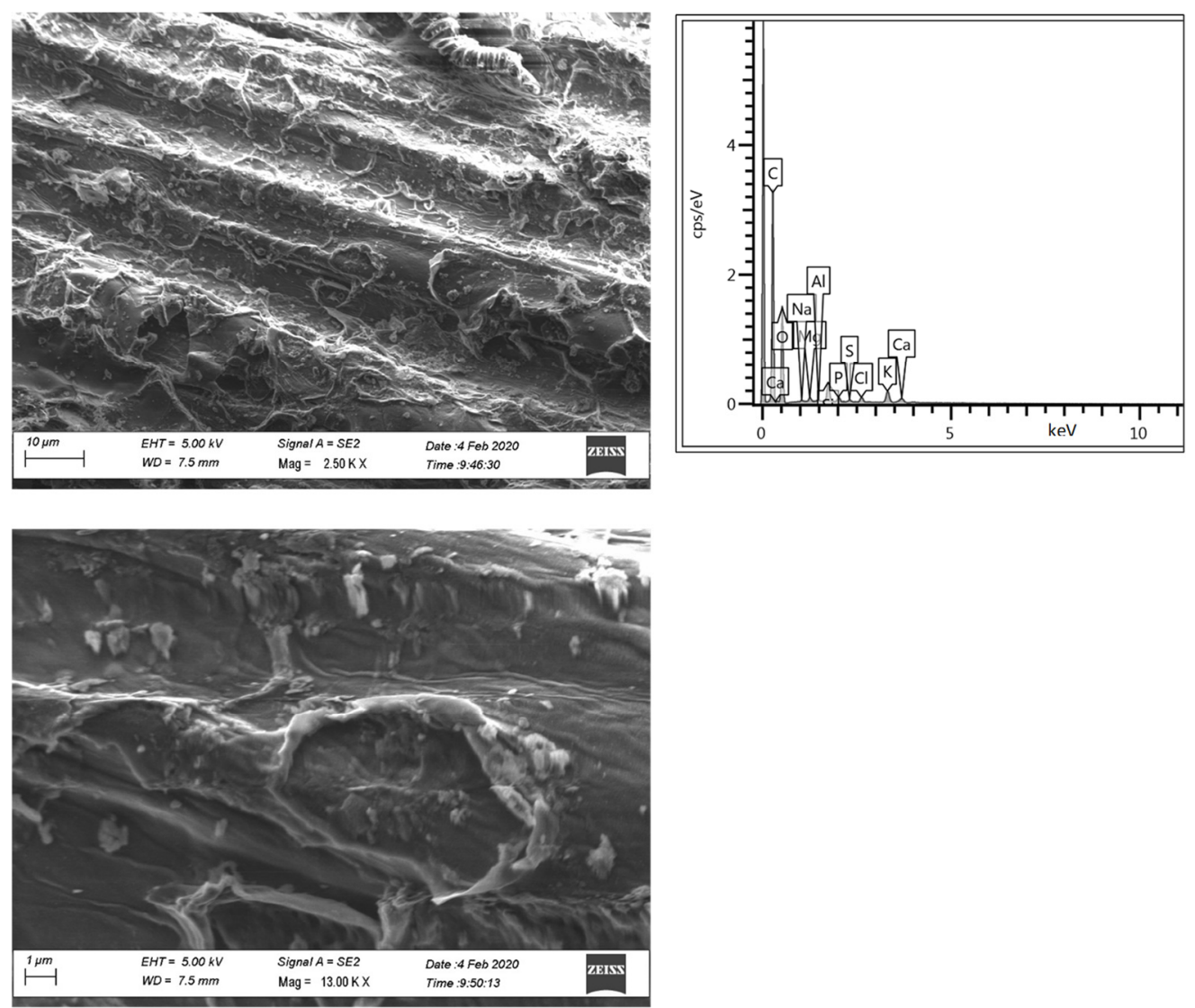

Figure 1. Scanning electron microscopy (SEM) images and energy-dispersive X-ray (EDX) spectrum of the digestate sample at magnifications of 2500 (top) and 13,000 (bottom) times. Images were taken with secondary electrons.

The FTIR spectrum of the DIG after interaction with the four molecules appeared not to be informative as it showed no evident modifications in the bands/peaks wavenumbers and relative intensity compared to that of the original DIG, except for the strong peak at $1385 \mathrm{~cm}^{-1}$ possibly due to the presence of phenolic $\mathrm{O}-\mathrm{H}$ and $\mathrm{C}-\mathrm{O}$ in the four molecules. However, this result is not surprising given the low concentrations of the molecules used in the interaction and the richness and strong intensity of the bands/peaks of the DIG. 


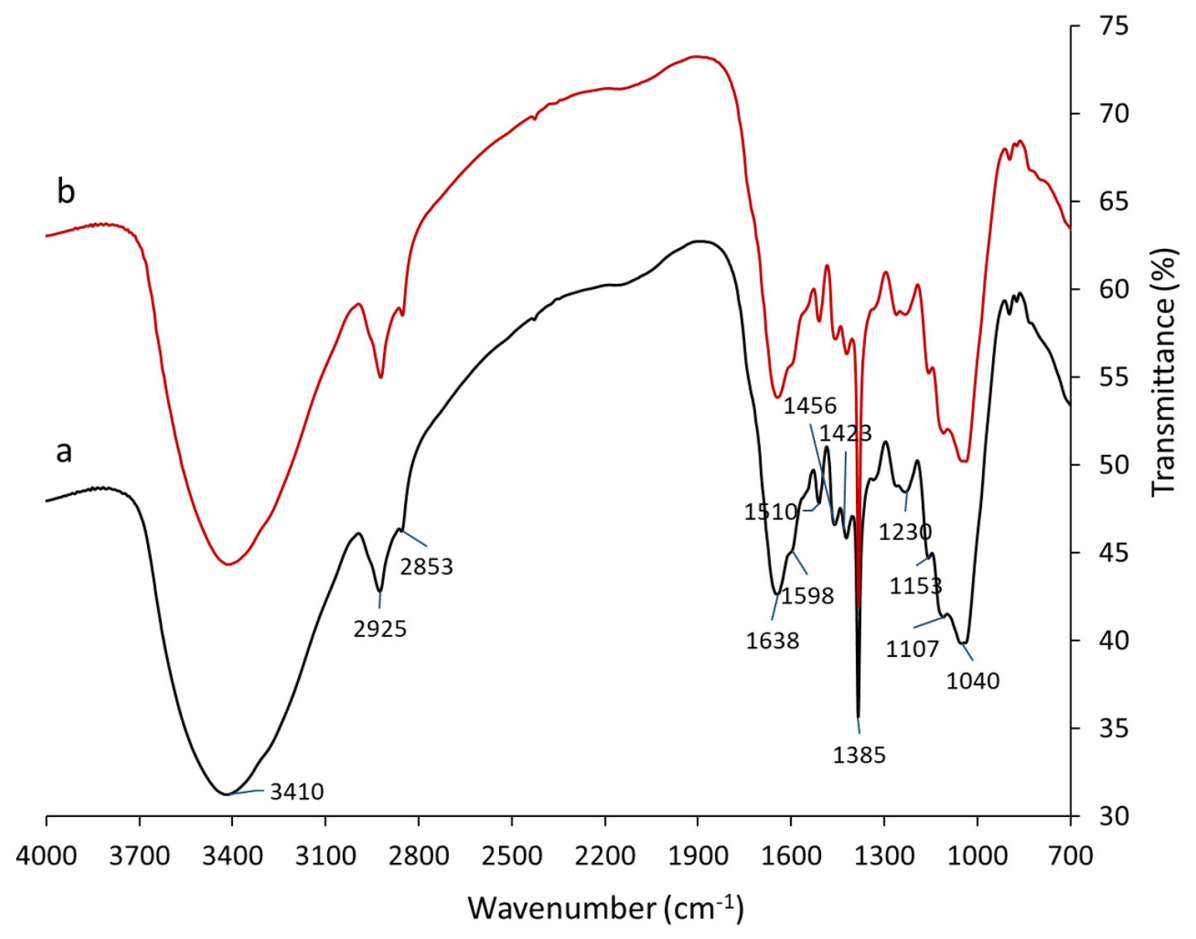

Figure 2. FTIR spectra of the DIG before (a) and after (b) adsorption of the compounds.

\subsection{Preliminary Adsorption Experiments}

The amounts of each compound adsorbed on DIG at equilibrium are reported in Figure 3 and Table 3. The different solution/adsorbent ratios adopted are quite common and comparable with those used in similar studies $[8,27]$. By increasing the solution/DIG ratio from 100 to 500 , the adsorbed quantity of BOS, BPA and OP increased significantly with each subsequent ratio tested, whereas that of MET only increased to the solution/DIG ratio of 500 when the adsorption doubled, compared to that measured at the ratios of 100 and 200 (Table 3). It is reasonable to assume that, at low adsorbent dosage, more sorption sites were available, including the innermost and less accessible ones, for the molecules, especially the more hydrophobic BOS and OP, and, at high adsorbent dosage, fewer sites were available. In addition, in the case of MET, a relevant increase of the solution/DIG ratio favored the sorption extent, probably due to the reduced competition from water molecules. At the highest ratio (500), the percentages of MET, BPA, BOS and OP adsorbed on the DIG after 24-h interaction were approximately $11,45,24$ and $66 \%$ of the initial compound added $(40 \mu \mathrm{g})$, respectively. Recently, Yao et al. [35], investigating the capacity of a DIG to remove various dyes from a wastewater, reported an increase in the adsorption capacity as the solution/DIG ratio increased. The authors commented that this could be due to the large number of sites not occupied by the dye when the DIG was at a high dosage, thus reducing the adsorption capacity of the latter [35]. Considering the physicochemical properties of the four molecules, as expected, the affinity for the DIG (MET $<$ BPA $<$ BOS $<\mathrm{OP})$ was inversely related to their solubility in water. In fact, it is well known that an organic solute is more adsorbable by a substrate the weaker its interaction with the solvent is. A negative correlation was already demonstrated between the sorption efficiency of carbon-rich materials and the water solubility of some EDCs and pesticides [24]. Based on these results, the highest ratio was chosen for the subsequent sorption experiments. 


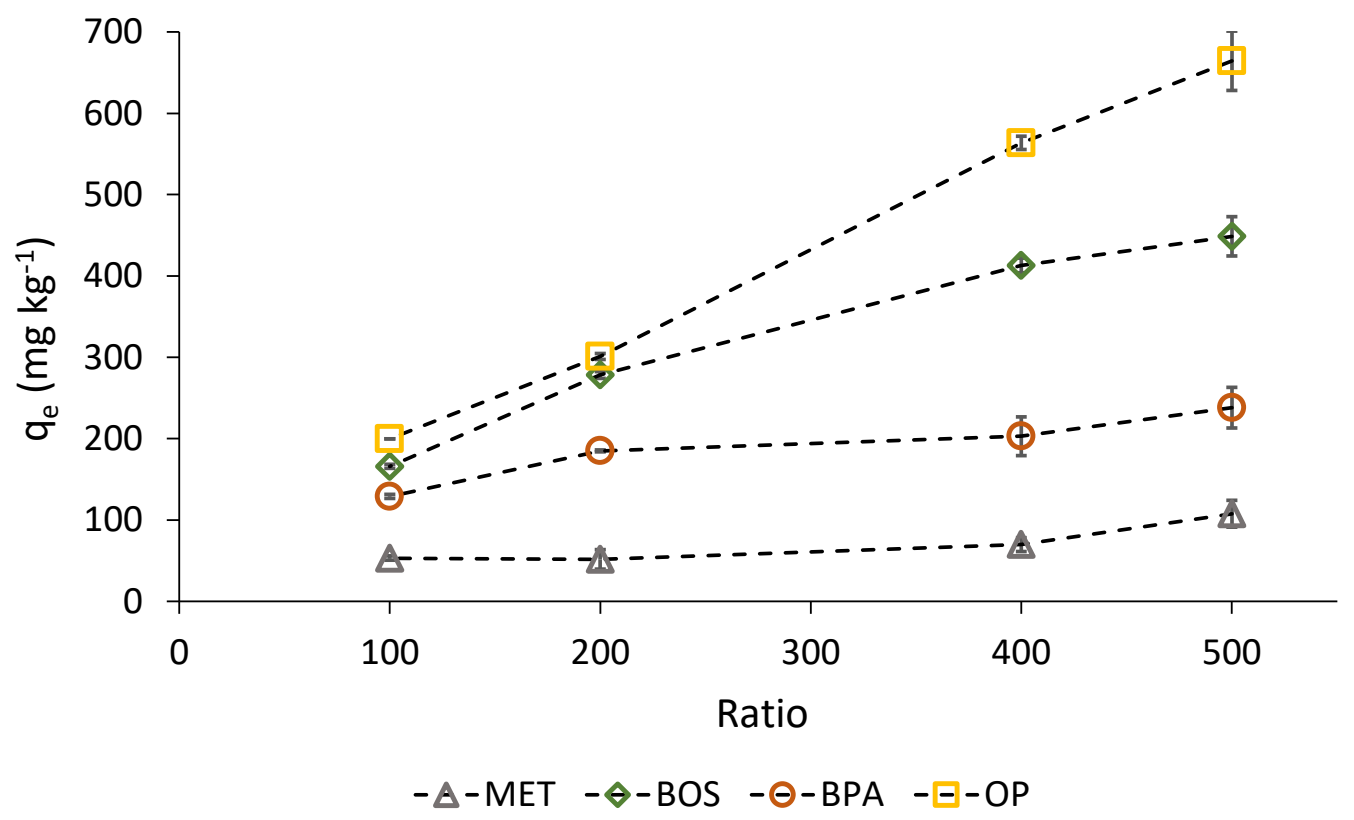

Figure 3. Adsorption of metribuzin (MET), boscalid (BOS), bisphenol A (BPA) and 4-tert-octylphenol $(\mathrm{OP})$ from water on the digestate at equilibrium concentration using different solution/adsorbent ratios.

Table 3. Amount of compound adsorbed $\left(\mathrm{mg} \mathrm{kg}^{-1}\right)$ as a function of the solution/digestate ratio adopted.

\begin{tabular}{ccccc}
\hline Compound & $\mathbf{1 0 0}$ & $\mathbf{2 0 0}$ & $\mathbf{4 0 0}$ & $\mathbf{5 0 0}$ \\
\hline MET & $53.11 \pm 2.65 \mathrm{~B}$ & $51.56 \pm 11.88 \mathrm{~B}$ & $69.83 \pm 8.42 \mathrm{~B}$ & $107.78 \pm 16.42 \mathrm{~A}$ \\
\hline BOS & $165.99 \pm 2.23 \mathrm{D}$ & $278.19 \pm 4.19 \mathrm{C}$ & $412.97 \pm 8.72 \mathrm{~B}$ & $448.74 \pm 24.12 \mathrm{~A}$ \\
\hline BPA & $128.88 \pm 2.48 \mathrm{D}$ & $184.99 \pm 1.25 \mathrm{C}$ & $203.08 \pm 24.04 \mathrm{~B}$ & $238.20 \pm 25.04 \mathrm{~A}$ \\
\hline OP & $200.00 \pm 0.12 \mathrm{D}$ & $301.11 \pm 3.65 \mathrm{C}$ & $563.65 \pm 8.15 \mathrm{~B}$ & $664.51 \pm 36.52 \mathrm{~A}$ \\
\hline
\end{tabular}

Note: data were analyzed by ANOVA and means were separated by the Duncan's new multiple range test at $P \leq 0.01(\mathrm{n}=3)$.

Although, as expected, the extent of DIG sorption in this study was somehow lower than that of biochar for MET [26,27,36], BOS [8], BPA [37] and OP [24], it can be considered remarkable and suggests a valuable use of this material as biosorbent. To the best of our knowledge, the literature does not report information on the removal of the four molecules studied by the DIG alone. The only comparable study found in the literature is that of Mukherjee et al. [8], who used soil/DIG biomixtures to remove some pesticides, including BOS.

\subsection{Adsorption Kinetics}

The study of adsorption kinetics allows the evaluation of the retention rate of the solute on the substrate in a certain period and provides useful information on the type of interaction. Based on the kinetics curves of adsorption obtained, it was evident that each molecule reached the steady state in a relatively short time. The Student's $t$-test applied to the quantities of compound adsorbed by the DIG at each time stated that the equilibrium times were $4 \mathrm{~h}$ for MET, BPA and OP and $8 \mathrm{~h}$ for BOS (Figure 4). The longer equilibrium time shown by BOS, compared to the other three molecules, might be due to its larger size. Then, subsequent adsorption isotherms of all compounds were performed using a contact time of $16 \mathrm{~h}$ between the substrate and the solution. The shapes of the kinetics curves indicate that the adsorption was a multi-step process, comprising a first rapid adsorption of the compounds on the most available external sites of the material followed by a slower sorption on the innermost active sites. Upon reaching the equilibrium condition, the 
maximum sorption concentration of $106.20 \pm 4.77,591.61 \pm 11.89,208.87 \pm 11.49$ and $712.80 \pm 2.47 \mathrm{mg} \mathrm{kg}^{-1}$ were measured for MET, BOS, BPA and OP, respectively (Figure 4 and Table 4). Statistical treatment of these data (ANOVA and Duncan's test) showed a high significant difference $(P \leq 0.01)$ among the amounts of compounds adsorbed at equilibrium (Table 4). The two less water-soluble BOS and OP showed the greatest affinity for the DIG sample, their concentration on the material being about 6 and 7 times higher, respectively, than that of MET. The lower adsorption of MET on organic substrates, compared to other pesticides and ECDs, is generally responsible for the high mobility of MET in soil and sediments and the consequent dangerous release into natural waters [15].

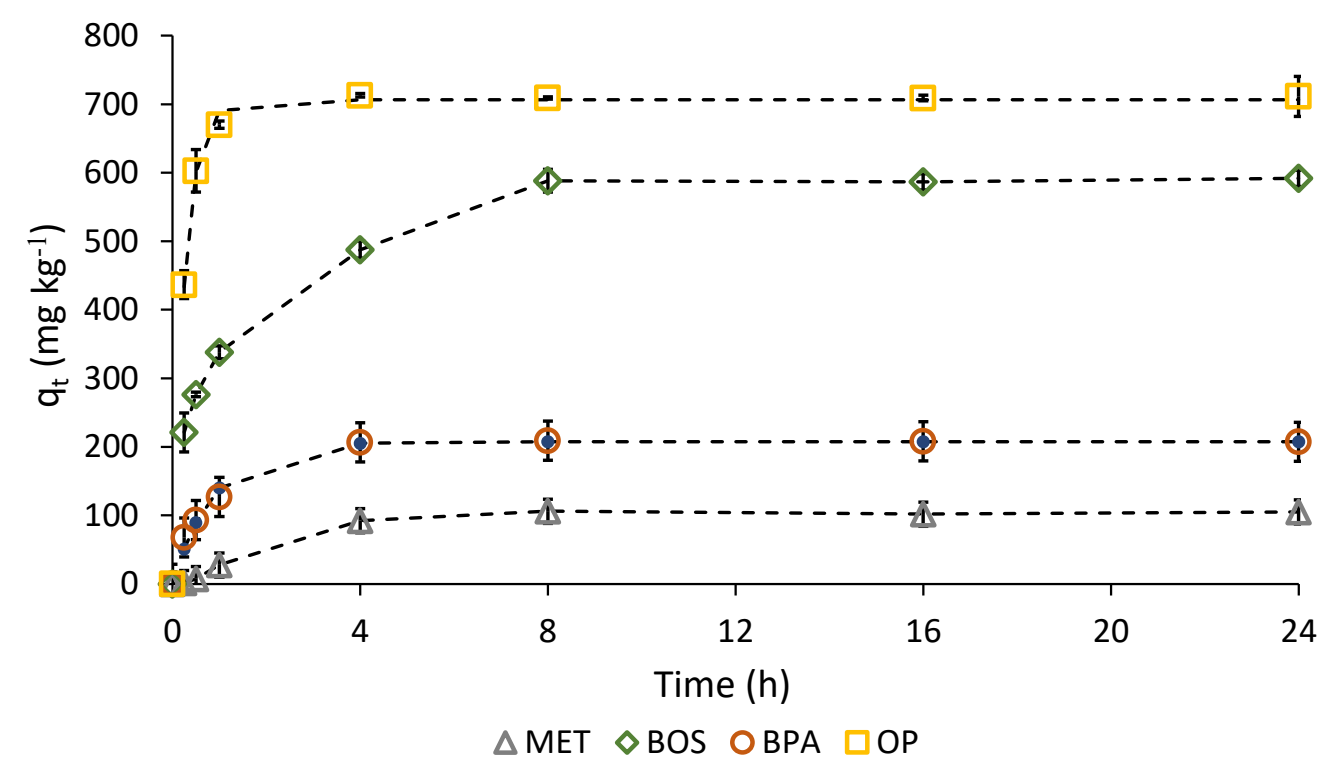

Figure 4. Adsorption kinetics data and plots of predicted pseudo-first-order kinetics of metribuzin (MET), bisphenol A (BPA) and 4-tert-octylphenol (OP) and predicted pseudo-second-order kinetics of boscalid (BOS) onto the digestate. Standard error is reported as vertical bar on each point $(n=3)$.

Table 4. Kinetic pseudo-first-order and pseudo-second-order parameters obtained through the non-linear method for the adsorption of the compounds onto the digestate.

\begin{tabular}{|c|c|c|c|c|c|c|c|c|c|}
\hline \multirow{2}{*}{ Compound } & \multicolumn{5}{|c|}{ Pseudo-First-Order } & \multicolumn{4}{|c|}{ Pseudo-Second-Order } \\
\hline & $\begin{array}{c}\mathrm{q}_{\text {e,experimental }} \\
\left(\mathrm{mg} \mathrm{kg}^{-1}\right)\end{array}$ & $\mathbf{r}$ & SSR & $\begin{array}{c}\mathrm{qe}, 1 \\
\left(\mathrm{mg} \mathrm{kg}^{-1}\right)\end{array}$ & $\begin{array}{c}k_{1} \\
\left(h^{-1}\right)\end{array}$ & $\mathbf{r}$ & SSR & $\begin{array}{c}\mathrm{qe}, 2^{-1} \\
\left(\mathrm{mg} \mathrm{kg}^{-1}\right)\end{array}$ & $\begin{array}{c}\mathrm{k}_{2} \\
\left(\mathrm{~kg} \mathrm{mg}^{-1} \mathrm{~h}^{-1}\right)\end{array}$ \\
\hline MET & 106.20 D & 0.985 & 339 & 107.17 & 0.372 & 0.965 & 793 & 124.78 & 0.003 \\
\hline BOS & $591.61 \mathrm{C}$ & 0.958 & 16,199 & 561.81 & 1.217 & 0.983 & 5525 & 601.64 & 0.003 \\
\hline BPA & 208.87 B & 0.991 & 485 & 207.53 & 1.125 & 0.990 & 472 & 221.21 & 0.007 \\
\hline $\mathrm{OP}$ & $712.80 \mathrm{~A}$ & 0.996 & 513 & 706.35 & 3.801 & 0.971 & 3450 & 728.61 & 0.010 \\
\hline
\end{tabular}

Note: experimental data at equilibrium were analyzed by ANOVA and the means were separated by the Duncan's new multiple range test at $P \leq 0.01(\mathrm{n}=3)$.

To investigate the adsorption mechanisms of the compounds onto the DIG, the kinetic data were analyzed using the non-linearized forms of the pseudo-first-order (Equation (2)) and pseudo-second-order (Equation (3)) models. Both models are widely applied in the study of AOPs' adsorption on organic and mineral substrates [32,38,39]. Table 4 shows the values of the kinetics parameters of the molecules according to the two models along with the correlation coefficients, $r$, and the sum of squared residuals, SSR. High $r$ values and low SSR values indicate the adequacy of the model to the experimental data. Based on the $r$ values, MET and OP preferentially followed the pseudo-first-order model and BOS followed the pseudo-second-order model, whereas BPA fitted both models well (Table 4). This was confirmed by the SSR values. Figure 4 shows the sorption kinetics data and 
plots of the predicted pseudo-first-order kinetics of MET, BPA and OP and the predicted pseudo-second-order kinetics of BOS.

The pseudo-first-order kinetics suggest a prevailing role of the adsorbent capacity [32]. The pseudo-second-order kinetics is based on sorption equilibrium capacity and assumes that the rate-limiting step is a chemisorption process involving valency forces through the sharing or exchange of electrons between the adsorbent and the sorbate $[38,39]$. The lignocellulosic fraction of the DIG may have interacted with the different molecules through various mechanisms, such as weak physisorption through van der Waals forces and hydrogen bonding and chemisorption through strong ionic or covalent bonds. As far as we know, there are no other studies on the sorption kinetics of the molecules examined here onto DIG. A recent work reported that the adsorption of MET on different chars was better described by the pseudo-second-order model [27]. This suggests an important role of the sorbent properties on the type of interaction prevailing between a solute and the substrate. Essandoh et al. [36], studying the adsorption of MET on biochar, concluded that the adsorption mechanism of MET could be explained mainly by hydrogen bonds and Coulombic forces and a minor contribution of van der Waals, dipole-dipole and $\pi-\pi$ interactions.

Although, in these experiments, no significant relationship was calculated between the amounts of the molecules adsorbed at equilibrium and the corresponding log Kow or water solubility, it was evident that the greatest removals by the DIG were obtained with the most hydrophobic OP and BOS.

\subsection{Adsorption and Desorption Isotherms}

The adsorption isotherm describes quantitatively the interaction between an adsorbent and a sorbate at a fixed temperature. It allows the evaluation of the adsorption parameters, such as the adsorption constant and the maximum adsorption, and provides indications on the allocation of the sorbate on sorbent sites. Different sorption models were adopted to fit the experimental adsorption and desorption data of the four compounds, such as the Freundlich, Langmuir, Temkin and Henry equations. Modeling of isotherm data is useful for predicting the adsorption mechanism. The Freundlich model can account for reversible adsorption on a heterogeneous substrate surface and is not limited to monolayer adsorption. Differently, the Langmuir equation is a good fit when the sorbent surface is homogeneous, the molecular interaction among the adsorbed species is negligible and the adsorption occurs as a monolayer on the adsorbent. The Temkin isotherm predicts a logarithmic reduction of available sites and sorptive energy and is best applied at intermediate concentrations.

The experimental sorption data obtained, along with the plots of the predicted Freundlich, Langmuir, Temkin and Henry equations, are shown in Figure 5. The sorption parameters calculated by fitting the equilibrium data in all four models and the desorption parameters calculated by fitting the experimental data in the Henry and Freundlich models are given in Tables 5 and 6, respectively. In addition to the values of the correlation coefficients (r), these tables show the values of the sum of squared residuals (SSR) that are an indicator of the matching of experimental data with the theoretical model (Tables 5 and 6). Higher $r$ values and lower SSR values indicate a better fit of the experimental data in the model.

Based on the calculated $r$ values over the whole concentration range tested, the sorption of MET was better described by the Freundlich model, whereas the sorption of the other three compounds better matched the Henry equation (Table 5). However, considering the SSR values, it was evident that, for all four compounds, the Freundlich model was the best fit because it reduced errors (lowest SSR), even if the differences among the SSR values of the four models were not always relevant (Table 5). Hence, the adsorption of each compound occurred through the multilayer formation on the heterogeneous surface of the DIG. Moreover, based on the exponent of the Freundlich equation, $1 / \mathrm{n}_{\mathrm{ads}}$, and according to Giles et al. [40], the isotherm of MET was L-shaped $(1 / \mathrm{n}<1)$, those of BPA and OP were C-type $(1 / \mathrm{n} \sim 1)$ and that of BOS was S-shaped $(1 / \mathrm{n}>1)$ (Table 5). A non-linear L-shaped 
Freundlich isotherm indicates that the compound has a high affinity for the sorbent in the initial stage of adsorption, while successively it decreases as adsorption sites are filled, and the process never reaches saturation. The L-shaped isotherm is typical of a solute of low hydrophobicity, such as MET (log Kow $=1.70)$, onto heterogeneous substrates. A C-type isotherm indicates a constant partitioning of the sorbate between the solution and the sorbent, without reaching saturation in the concentration range adopted. Finally, S-type isotherms are usually observed at low concentrations and indicate an increasing adsorption rate as the concentration of the sorbate in solution increases. The S-type isotherm is typical of adsorbents having high affinity for the solvent, e.g., water competes with the solute for adsorption sites [40]. The Freundlich exponent $(1 / \mathrm{n})$ is related to the strength and feasibility of the adsorption. The reciprocal $n$ is the heterogeneity factor. Based on $1 / n$ value, the process can be considered mainly physical when $1 / \mathrm{n}<1$, chemical when $1 / \mathrm{n}>1$ and linear if $1 / \mathrm{n}$ is equal to 1 [41]. Thus, the low $1 / \mathrm{n}$ value obtained for MET suggests that the adsorption on the DIG was predominantly physical (Table 5). Differently, the high $1 / \mathrm{n}$ value for BOS suggests a chemisorption process. The $1 / \mathrm{n}$ values of the two phenolic molecules, BPA and OP, were not very different from the unit (Table 5). These findings agree with the results obtained in the kinetic study. Based on the structure and functional groups of the molecules used in the mixture (very weak organic acids or bases) in this study, no interactions between/among them can be expected. AOPs may interact with organic matter $(\mathrm{OM})$ in several ways which affect both the retention capacity of the adsorbent and the rate of desorption. In general, AOPs can be adsorbed to OM through specific physical and chemical binding mechanisms and forces with varying degrees and strengths, which include ionic, hydrogen and covalent bonding, charge-transfer or electron donor-acceptor mechanisms, dipole-dipole and van der Waals forces, ligand exchange and cation and water bridging [42]. The capacity of DIG to retain organic compounds is essentially due to the numerous hydrophobic and hydrophilic surface sites and chemically reactive functional groups, such as carboxylic and phenolic $\mathrm{OH}$, alcoholic $\mathrm{OH}$, ketonic $\mathrm{C}=\mathrm{O}$, amine groups and so on, where the molecules can be linked with bonds of different type and strength. For example, DIG sites containing $\mathrm{O}$ and N- can form hydrogen bonds with molecules containing suitable complementary groups. This can happen for MET that, at the $\mathrm{pH}$ of this study, is almost all unprotonated. The adsorption of MET onto different biosorbents has been mainly ascribed to $\mathrm{H}$ bonds and Coulombic forces and, to a lesser extent, to van der Waals and dipole-dipole interactions [36]. It is likely that the non-polar BOS molecule interacted with DIG through hydrophobic interaction [8]. Phenolic groups of BPA and OP can interact through electron donor-acceptor mechanisms or charge-transfer, by binding with complementary groups of DIG. However, adsorption of low-polar AOPs can also occur through non-specific hydrophobic or partitioning processes between water and the OM phase, in particular on hydrophobic active sites of OM, such as aliphatic side chains and aromatic structures [42]. OP has been proven to bind to organic materials through covalent and $\mathrm{H}$ bonds [24]. The presence of strong and weak binding of various phenolic EDCs to organic matter has been reported [42]. Finally, the mechanisms and the extent of adsorption certainly depend on the solution/adsorbent ratio, the physical and chemical properties of both the solute and the adsorbent and the condition of the medium, such as $\mathrm{pH}$ and ionic strength. 


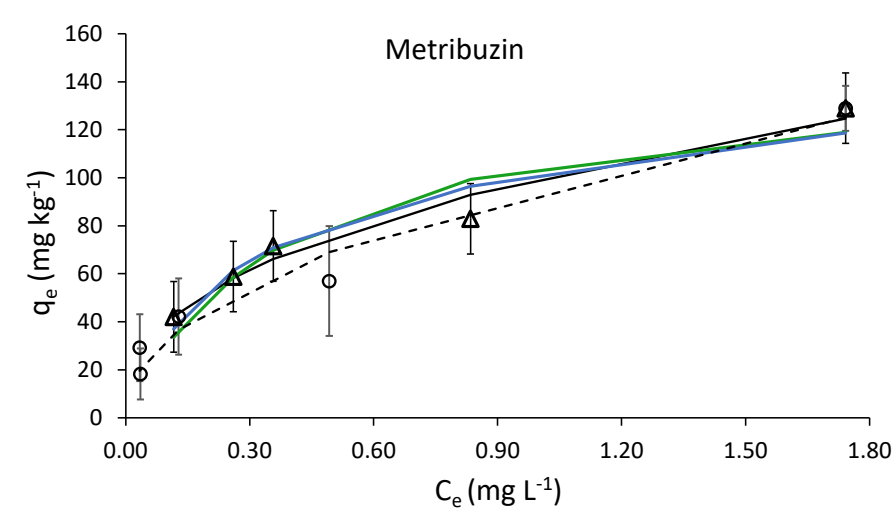

$\Delta$ Exp. ads — Freundlich — Langmuir — Temkin O Exp. des ---Freundlich

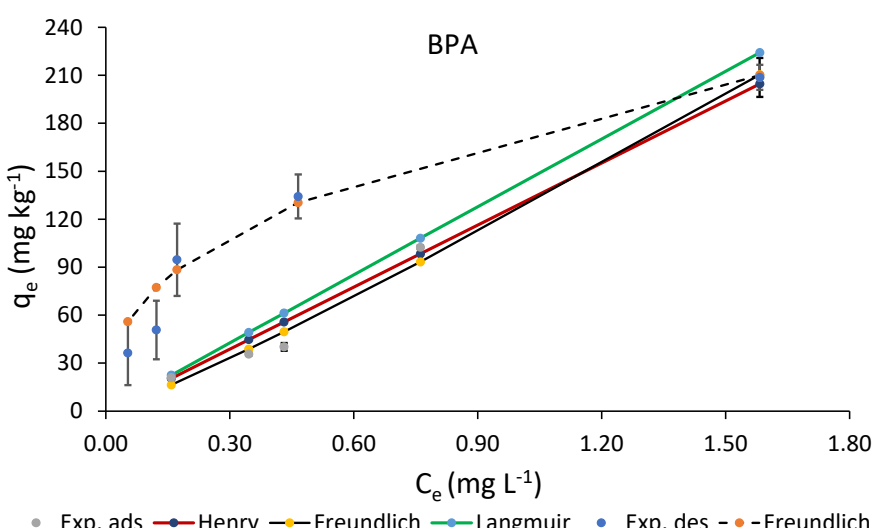

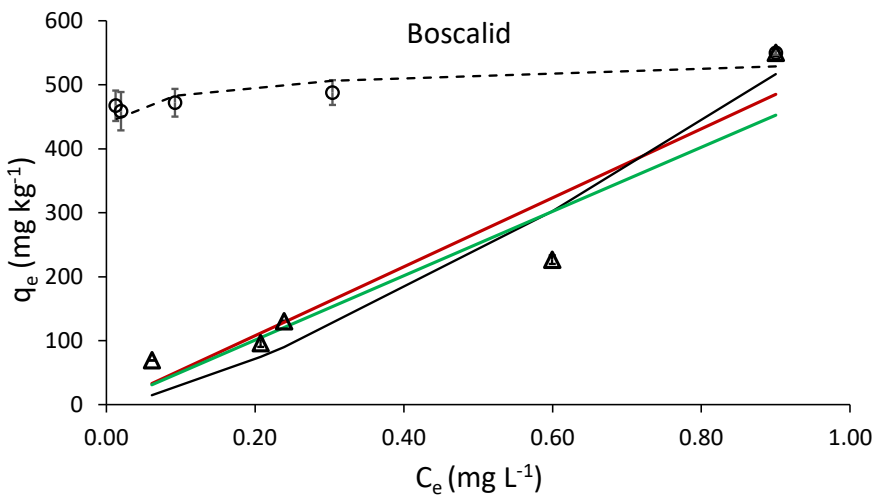

$\Delta$ Exp.ads — Henry — Freundlich — Langmuir O Exp. des ---Freundlich

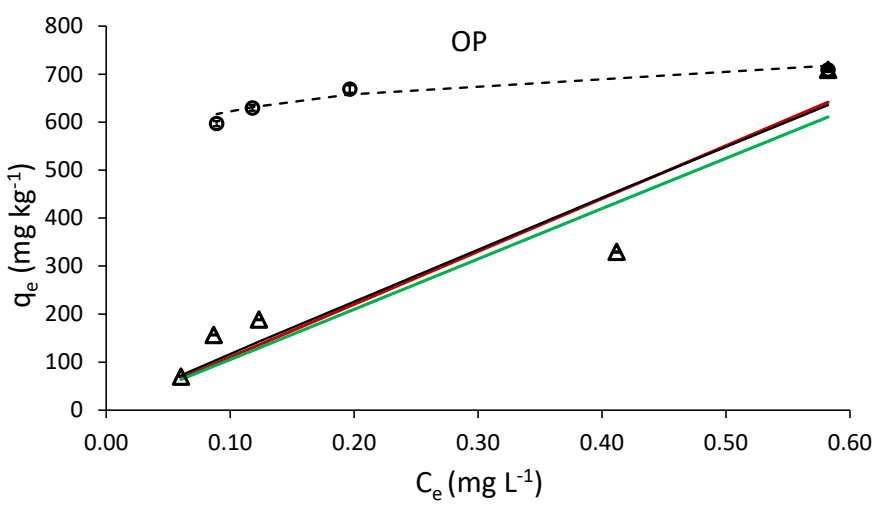

$\Delta$ Exp. ads — Henry — Freundlich — Langmuir O Exp. des ---Freundlich

Figure 5. Adsorption (experimental points and solid lines representing plots of Henry, Freundlich, Langmuir and Temkin models) and desorption (experimental points and dashed lines representing plot of Freundlich model) isotherms of the compounds on the digestate. Standard error is reported as vertical bar on each point $(n=3)$.

As far as we know, there are no studies concerning the adsorption of the four compounds used here on the DIG, and therefore it is not possible to compare our results with those of the literature. The adsorption of MET on various plant-based chars was well interpreted by L-shaped Freundlich isotherms [27]. In a recent work, BOS adsorption on different sediments followed a Freundlich model [43], and the same model was the best fit for OP on an aquifer material [44] and various carbon-rich substrates [24].

The Henry isotherm (Equation (8)) allowed the calculation of the distribution coefficient $K_{d}$ that is a reliable parameter to express the sorption efficiency of a substrate. The adsorption parameters $\left(K_{d \text { ads }}, K_{F}\right.$ ads and $\left.1 / n_{\text {ads }}\right)$ and the coefficient $K_{O C}$ ads for the four compounds are referred to in Table 5 . The adsorption constants $\mathrm{K}_{\mathrm{d} \text { ads }}, \mathrm{K}_{\mathrm{F}}$ ads and $\mathrm{K}_{\mathrm{OC}}$ ads followed the same order: MET $<\mathrm{BPA}<\mathrm{BOS}<\mathrm{OP}$ (Table 5). The $\mathrm{K}_{\mathrm{F}}$ ads value of the more hydrophobic OP was approximately 11 times higher than that of the more water-soluble MET (Table 5). The values of the normalized organic carbon, $\mathrm{K}_{\mathrm{OC}}$ ads, of the four compounds varied widely from 170 for the least hydrophobic MET to 2180 for the most hydrophobic OP, which are comparable to the values found in the literature $[8,27,36,43,44]$. The interpretation of the adsorption data with Langmuir's equation allowed the calculation of the maximum adsorption, $b$. On the basis of the $b$ values, the adsorption trend was the following: BOS > OP > BPA > MET. The Temkin model is applied for an intermediate concentration range and takes into account the interaction between the sorbate and the adsorbent. It assumes that the heat of adsorption of the sorbate decreases linearly with the surface coverage. From the Temkin plot, the parameters estimated were $A_{T}, B$ and $b_{T}$ (Table 5). When the Temkin equation was used to fit the experiment data, a good match was obtained only for MET with $r=0.962$, though this value was lower than in the Freundlich model (Table 5). The plot of the Temkin model for MET is depicted in Figure 5. Much lower $r$ values were obtained for the other compounds, indicating that the Temkin model was not 
appropriate for BPA, OP and, especially, BOS. The parameter B gives an indication of the heat of adsorption; for each molecule, especially the most hydrophobic ones, it was quite high, suggesting an exothermic sorption process of the molecules on the DIG [41].

Unfortunately, there is no information in the literature on the extent and modeling of adsorption of these molecules on DIG, and this does not make a comparison possible. In a recent study, Gaullier et al. [43] reported $\mathrm{K}_{\mathrm{F} \text { ads }}$ values for BOS on sediments ranging from 2.8 to $13.5 \mathrm{mg} \mathrm{kg}^{-1}$. The $\mathrm{K}_{\mathrm{OC}}$ ads value calculated in this study for MET on DIG $\left(170 \mathrm{~L} \mathrm{~kg}^{-1}\right)$ was almost twice and $73 \%$, respectively, of those found averagely for the adsorption of MET on vermicompost $\left(93 \mathrm{~L} \mathrm{~kg}^{-1}\right)$ and hydrochar $\left(232 \mathrm{~L} \mathrm{~kg}^{-1}\right)$ [27]. The $\mathrm{K}_{\mathrm{OC}}$ ads value of BOS calculated here $\left(1066 \mathrm{~L} \mathrm{~kg}^{-1}\right.$ ) was much higher than that reported for the adsorption of BOS on a biomixture of $30 \%$ of DIG and soil [8]. Ying et al. [44] studied the adsorption of various EDCs on a sediment and reported $\mathrm{K}_{\mathrm{F} \text { ads }}$ values of 3.89 and $90.9 \mathrm{~L} \mathrm{~kg}^{-1}$ for BPA and $\mathrm{OP}$, respectively.

Table 5. Adsorption parameters of the compounds on the digestate.

\begin{tabular}{|c|c|c|c|c|c|c|c|c|c|c|c|c|c|c|c|c|c|}
\hline \multirow[b]{2}{*}{ Compound } & \multicolumn{4}{|c|}{ Henry Model } & \multicolumn{4}{|c|}{ Freundlich Model } & \multicolumn{4}{|c|}{ Langmuir Model } & \multicolumn{5}{|c|}{ Temkin Model } \\
\hline & $\mathbf{r}$ & SSR & $\begin{array}{c}\mathrm{K}_{\mathrm{d}} \\
\left(\mathrm{L} \mathrm{kg}^{-1}\right)\end{array}$ & $\begin{array}{c}\mathrm{K}_{\mathrm{OC}} \\
\left(\mathrm{L} \mathrm{kg}^{-1}\right)\end{array}$ & $\mathbf{r}$ & SSR & $\begin{array}{c}\mathrm{K}_{\mathrm{F} \text { ads }} \\
\left(\mathrm{L} \mathrm{kg}^{-1}\right)\end{array}$ & $1 / n_{\text {ads }}$ & $\mathrm{r}$ & SSR & $\underset{(\mathrm{mg} \mathrm{kg}-1)}{\mathrm{b}}$ & $\begin{array}{c}\mathrm{K}_{\mathrm{L}} \\
\left(\mathrm{L} \mathrm{mg}^{-1}\right)\end{array}$ & $\mathrm{r}$ & SSR & $\begin{array}{c}\mathrm{A}_{\mathrm{T}} \\
\left(\mathrm{L} \mathrm{kg}^{-1}\right)\end{array}$ & $\underset{\left(\mathrm{J} \mathrm{mol}^{-1}\right)}{\text { B }}$ & $\mathbf{b}_{\mathrm{T}}$ \\
\hline MET & 0.930 & 4588 & 86.19 & 170.50 & 0.983 & 147 & 99.88 & 0.40 & 0.954 & 445 & 145 & 2.587 & 0.962 & 322 & 29.46 & 30.12 & 80.87 \\
\hline BOS & 0.980 & 15,049 & 538.73 & 1065.74 & 0.968 & 11872 & 593.88 & 1.32 & 0.948 & 15,130 & 126,113 & 0.004 & 0.815 & 51,869 & 14.57 & 153.57 & 15.86 \\
\hline BPA & 0.997 & 354 & 129.20 & 255.59 & 0.996 & 205 & 126.31 & 1.11 & 0.992 & 361 & 47,424 & 0.003 & 0.925 & 3459 & 5.44 & 83.15 & 29.30 \\
\hline $\mathrm{OP}$ & 0.980 & 26,465 & 1102.09 & 2180.20 & 0.951 & 26,322 & 1067.82 & 0.96 & 0.953 & 26,528 & 117,129 & 0.009 & 0.903 & 46,769 & 20.54 & 229.41 & 10.62 \\
\hline
\end{tabular}

Table 6. Desorption parameters of the compounds from the digestate.

\begin{tabular}{|c|c|c|c|c|c|c|c|c|c|}
\hline \multirow[b]{2}{*}{ Compound } & \multicolumn{4}{|c|}{ Henry Model } & \multicolumn{4}{|c|}{ Freundlich Model } & \multirow[b]{2}{*}{$\mathbf{H}$} \\
\hline & $\mathbf{r}$ & SSR & $\begin{array}{c}\mathrm{K}_{\mathrm{d} \text { des }} \\
\left(\mathrm{L} \mathrm{kg}^{-1}\right)\end{array}$ & $\begin{array}{l}\mathrm{K}_{\mathrm{OC}} \text { des } \\
\left(\mathrm{L} \mathrm{kg}^{-1}\right)\end{array}$ & $\mathbf{r}$ & SSR & $\begin{array}{c}\mathrm{K}_{\mathrm{F} \text { des }} \\
\left(\mathrm{L} \mathrm{kg}^{-1}\right)\end{array}$ & $1 / n_{\text {des }}$ & \\
\hline MET & 0.947 & 2369 & 78.80 & 155.88 & 0.982 & 287 & 96.35 & 0.47 & 1.175 \\
\hline BOS & 0.673 & 651,881 & 769.65 & 1522.55 & 0.874 & 1287 & 531.02 & 0.04 & 0.030 \\
\hline $\mathrm{BPA}$ & 0.904 & 14,170 & 151.70 & 300.10 & 0.994 & 170 & 175.59 & 0.39 & 0.351 \\
\hline OP & 0.753 & 889,423 & 1709.20 & 3381.21 & 0.963 & 507 & 749.07 & 0.08 & 0.083 \\
\hline
\end{tabular}

The experimental desorption data and the Freundlich plots for the four compounds are shown in Figure 5, while the desorption coefficients of Henry $\left(\mathrm{K}_{\mathrm{d} \text { des }}\right.$ and $\left.\mathrm{K}_{\mathrm{OC} \text { des }}\right)$ and Freundlich $\left(\mathrm{K}_{\mathrm{F} \text { des }}\right.$ and $\left.1 / \mathrm{n}_{\text {des }}\right)$ are given in Table 6 . When desorption data were fitted to both Henry and Freundlich equations, based on both $r$ and SSR indicators, the Freundlich model was the best fit for all compounds (Table 6). In all cases, the desorption isotherm was L-type $\left(1 / \mathrm{n}_{\text {des }}<1\right)$. After four desorption steps, approximately $86,17,74$ and $16 \%$ of the initially retained MET, BOS, BPA and OP were desorbed from the DIG, respectively. The values of $\mathrm{K}_{\mathrm{F} \text { des }}$ for $\mathrm{BOS}$ and $\mathrm{OP}$ were lower than the corresponding values of $K_{F}$ ads, suggesting a partial reversibility of the process. Comparing the values of $1 / \mathrm{n}$ des and $1 / \mathrm{n}$ ads, we found that for MET alone the desorption rate was slightly higher than the adsorption rate $\left(1 / \mathrm{n}_{\text {des }}>1 / \mathrm{n}_{\mathrm{ads}}\right)$, whereas the desorption of all the other compounds occurred very slowly and was incomplete (Table 6). This behavior is clearly shown in Figure 5. In other words, the DIG demonstrated a good capacity to retain MET, but also an easy release (negative hysteresis, $\mathrm{H}>1$ ) as soon as the liquid phase was diluted. This was easily predictable considering the physicochemical properties of MET, such as the low $\log$ Kow and high water solubility. Differently, the other three molecules were difficult to desorb from the DIG, denoting a strong sequestration and a significant positive hysteresis $(\mathrm{H}<1)$ (Table 6). The formation of covalent bonds could be the reason for the low desorption rate and the hysteresis phenomenon observed for these molecules. These results suggest that the type of interaction between MET and the DIG was weaker than that formed between the other three compounds and the DIG. We can assume that the 
more hydrophobic molecules were retained through high-energy bonds which hindered their reversibility. The marked retention of BOS, BPA and OP by the DIG and the low desorption, especially for BOS and OP, are reasonably due to their chemical structures and hydrophobic character. In particular, the large size and the low water solubility of BOS can explain the very low release observed. The desorption of BOS from a 30\% DIG/soil mixture was almost negligible after three desorption steps [8]. Studying the adsorption of BOS on sediments, Gaullier et al. [43] reported a scarce reversibility of this compound and explained this behavior with the formation of irreversible bonds between BOS and the organic fraction of the sediment.

Possible relationships between the sorption/desorption constants $\left(\mathrm{K}_{\mathrm{F} \text { ads }}, \mathrm{K}_{\mathrm{d} \text { ads }}, \mathrm{K}_{\mathrm{F} \text { des }}\right.$ and $\mathrm{K}_{\mathrm{d} \text { des }}$ ) and the corresponding physicochemical properties of the compounds, including water solubility and $\log$ Kow, were assessed through linear regressions. No significant correlations were obtained between each constant and water solubility, whereas all constants were sufficiently correlated with log Kow (Figure 6). This confirmed the crucial role of hydrophobicity in the interaction of AOPs with organic materials.

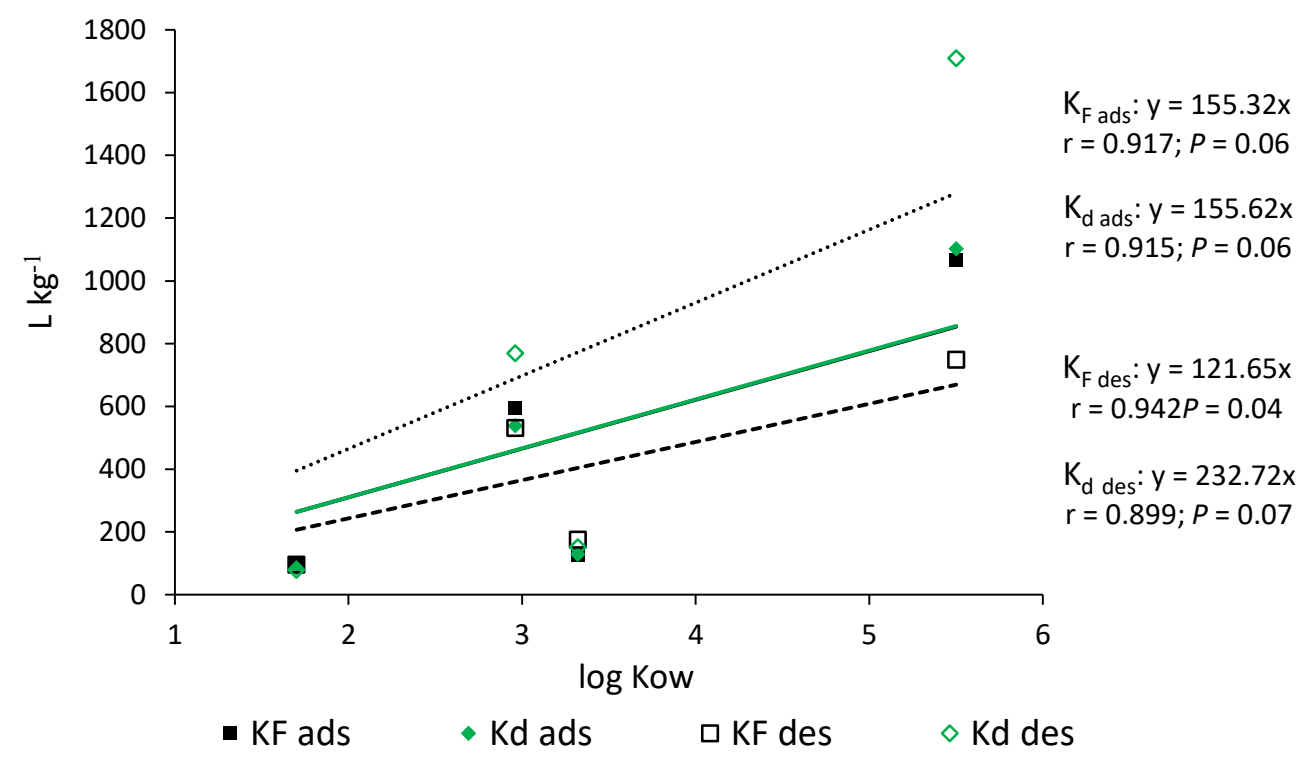

Figure 6. Plots of the correlations between the values of the adsorption and desorption constants, $\mathrm{K}_{\mathrm{F} \text { ads }}, \mathrm{K}_{\mathrm{d} \text { ads }}, \mathrm{K}_{\mathrm{F} \text { des }}$ and $\mathrm{K}_{\mathrm{d} \text { des}}$, of the four compounds and the corresponding $\log$ Kow.

\section{Conclusions}

Digestate (DIG), a by-product of the anaerobic biological conversion of waste biomass, is produced in increasing quantities and is a promising material for both agricultural and environmental applications. This study evaluated for the first time the capacity of DIG to remove from water four pollutants with endocrine-disrupting activity, namely two pesticides and two xenoestrogens. The DIG used showed a remarkable efficiency in adsorbing all compounds, especially the more hydrophobic OP and BOS. The sorption kinetic data of MET and OP preferentially fitted a pseudo-first-order kinetic equation and those of BOS followed a pseudo-second-order kinetic equation, whereas those of BPA fitted both models well. The extent of adsorption of the compounds on the DIG followed the order: $\mathrm{OP}>\mathrm{BOS}>\mathrm{BPA}>\mathrm{MET}$. The adsorption of BOS, BPA and OP were adequately described by both the Henry and Freundlich isotherms, whereas the adsorption of MET was better interpreted by the Freundlich model. The desorption rates of BOS, BPA and OP were lower than the adsorption rates, indicating strong retention of the compounds on the DIG and the occurrence of hysteretic conditions. Conversely, MET was easily and completely released from the DIG, denoting a slight negative hysteresis. The sorption/desorption constants $\mathrm{K}_{\mathrm{F}}$ and $\mathrm{K}_{\mathrm{d}}$ were sufficiently correlated with the hydrophobicity of the molecules. The overall results of this study evidenced the good potential of this material as a biosorbent of 
organic pollutants. Therefore, the incorporation of DIG into the soil can yield more than one benefit, such as reducing the bioavailability of pollutants for plants and microorganisms, counteracting the leaching of these compounds into groundwater and preventing their entry into the food chain.

Author Contributions: Conceptualization, E.L. and C.C.; methodology, C.C. and R.S.; software, E.L. and C.C.; validation, E.L., C.C. and R.S.; formal analysis, E.L. and C.C.; investigation, C.C., C.S. and R.S.; resources, E.L. and C.S.; data curation, C.C. and R.S.; writing-original draft preparation, E.L.; writing-review and editing, E.L.; visualization, E.L. and C.C.; supervision, E.L. and C.S.; project administration, E.L. and C.C.; funding acquisition, E.L. and C.S. All authors have read and agreed to the published version of the manuscript.

Funding: This research was funded by Ordinary Fund for Scientific Research of the University of Bari Aldo Moro, Italy.

Acknowledgments: The authors thank F.lli Caione Azienda Agricola La Quercia Società Coop., Foggia, Italy, for providing the digestate sample used in this study. The authors are grateful to the anonymous reviewers for their valuable comments and suggestions.

Conflicts of Interest: The authors declare no conflict of interest.

\section{References}

1. Singh, L.; Kalia, V.C. Waste Biomass Management—A Holistic Approach; Springer International Publishing AG: Cham, Switzerland, 2017. [CrossRef]

2. Fabbri, D.; Torri, C. Linking pyrolysis and anaerobic digestion (Py-AD) for the conversion of lignocellulosic biomass. Curr. Opin. Biotechnol. 2016, 38, 167-173. [CrossRef] [PubMed]

3. Wang, W.; Lee, D.-J. Valorization of anaerobic digestion digestate: A prospect review. Bioresour. Technol. 2021, 323, 124626. [CrossRef]

4. Zhang, Z.; Zhu, Z.; Shen, B.; Liu, L. Insights into biochar and hydrochar production and applications: A review. Energy 2019, 171, 581-598. [CrossRef]

5. Parlavecchia, M.; Carnimeo, C.; Loffredo, E. Soil amendment with biochar, hydrochar and compost mitigates the accumulation of emerging pollutants in rocket salad plants. Water Air Soil Pollut. 2020, 231, 554. [CrossRef]

6. Braguglia, C.M.; Gallipoli, A.; Gianico, A.; Pagliaccia, P. Anaerobic bioconversion of food waste into energy: A critical review. Bioresour. Technol. 2018, 248, 37-56. [CrossRef]

7. Peng, W.; Pivato, A. Sustainable management of digestate from the organic fraction of municipal solid waste and food waste under the concepts of back to earth alternatives and circular economy. Waste Biomass Valor. 2019, 10, 465-481. [CrossRef]

8. Mukherjee, S.; Weihermüller, L.; Tappe, W.; Hofmann, D.; Köppchen, S.; Laabs, V.; Vereecken, H.; Burauel, P. Sorption-desorption behaviour of bentazone, boscalid and pyrimenthanil in biochar and digestate based soil mixtures for biopurification systems. Sci. Total Environ. 2016, 559, 63-73. [CrossRef]

9. López-Pacheco, I.Y.; Silva-Núñez, A.; Salinas-Salazar, C.; Arevalo-Gallegos, A.; Lizarazo-Holguin, L.A.; Barcelo, D.; Iqbal, H.M.N.; Parra-Saldívar, R. Anthropogenic contaminants of high concern: Existence in water resources and their adverse effects. Sci. Total Environ. 2019, 690, 1068-1088. [CrossRef]

10. European Commission (EC) 2016. Defining Criteria for Identifying Endocrine Disruptors in the Context of the Implementation of the Plant Protection Products Regulation and Biocidal Products Regulation. Available online: https:/ /ec.europa.eu/transparency/ regdoc/rep/10102/2016/EN/SWD-2016-211-F1-EN-MAIN-PART-6.PDF (accessed on 13 July 2021).

11. European Commission (EC) 2020. Endocrine Disruptors. Available online: https://ec.europa.eu/environment/chemicals/ endocrine/index_en.htm (accessed on 13 July 2021).

12. Calafat, A.M.; Ye, X.; Wong, L.Y.; Reidy, J.A.; Needham, L.L. Exposure of the U.S. population to bisphenol A and 4-tertiaryoctylphenol: 2003-2004. Environ. Health Perspect. 2008, 116, 39-44. [CrossRef]

13. Diamanti-Kandarakis, E.; Bourguignon, J.-P.; Giudice, L.C.; Hauser, R.; Prins, G.S.; Soto, A.M.; Zoeller, R.T.; Gore, A.C. Endocrinedisrupting chemicals: An Endocrine Society scientific statement. Endocr. Rev. 2009, 30, 293-342. [CrossRef]

14. Silva, V.; Mol, H.G.J.; Zomer, P.; Tienstra, M.; Ritsema, C.J.; Geissena, V. Pesticide residues in European agricultural soils-A hidden reality unfolded. Sci. Total Environ. 2019, 653, 1532-1545. [CrossRef]

15. USEPA Office of Water Report 2003. Candidate Contaminant List Regulatory Determination Support Document for Metribuzin. Available online: https://www.epa.gov/sites/production/files/2014-09/documents/support_cc1_metribuzin_ccl_regdet.pdf (accessed on 13 July 2021).

16. USEPA Office of Pesticide Programs 2010. Environmental Fate and Ecological Risk Assessment for Boscalid New Use on Rapeseed, Including Canola (Seed Treatment). Available online: https://www3.epa.gov/pesticides/chem_search/cleared_reviews/csr_PC128008_23-Dec-10_a.pdf (accessed on 20 July 2021). 
17. Geens, T.; Aerts, D.; Berthod, C.; Bourguignon, J.-P.; Goeyens, L.; Lecomte, P.; Maghuin-Rogister, G.; Pironnet, A.-M.; Pussemier, L.; Scippo, M.-L.; et al. A review of dietary and non-dietary exposure to bisphenol-A. Food Chem. Toxicol. 2012, 50, 3725-3740. [CrossRef] [PubMed]

18. Olaniyan, L.W.B.; Okoh, O.O.; Mkwetshana, N.T.; Akoh, A.I. Environmental water pollution, endocrine interference and ecotoxicity of 4-tert-octylphenol: A review. Rev. Arch. Environ. Contam. Toxicol. 2018, 248, 81-109. [CrossRef]

19. Campbell, C.G.; Borglin, S.E.; Green, F.B.; Grayson, A.; Wozei, E.; Stringfellow, W.T. Biologically directed environmental monitoring, fate, and transport of estrogenic endocrine disrupting compounds in water: A review. Chemosphere 2006, 65, 1265-1280. [CrossRef] [PubMed]

20. Linhart, C.; Panzacchi, S.; Belpoggi, F.; Clausing, P.; Zaller, J.G.; Hertoge, K. Year-round pesticide contamination of public sites near intensively managed agricultural areas in South Tyrol. Environ. Sci. Eur. 2021, 33, 1. [CrossRef]

21. Fernandes, M.C.; Cox, L.; Hermosín, M.C.; Cornejo, J. Organic amendments affecting sorption, leaching and dissipation of fungicides in soils. Pest. Manag. Sci. 2006, 62, 1207-1215. [CrossRef] [PubMed]

22. Mojiri, A.; Zhou, J.L.; Robinson, B.; Ohashi, A.; Ozaki, N.; Kindaichi, T.; Farraji, H.; Vakili, M. Pesticides in aquatic environments and their removal by adsorption methods. Chemosphere 2020, 253, 126646. [CrossRef]

23. Senesi, N.; Loffredo, E.; D'Orazio, V.; Brunetti, G.; Miano, T.M.; La Cava, P. Adsorption of pesticides by humic acids from organic amendments and soils. In Humic Substances and Chemical Contaminants; Clapp, C.E., Hayes, M.H.B., Senesi, N., Bloom, P.R., Jardine, P.M., Eds.; John Wiley \& Sons, Inc.: Madison, WI, USA, 2015; pp. 129-153. [CrossRef]

24. Loffredo, E.; Taskin, E. Adsorptive removal of ascertained and suspected endocrine disruptors from aqueous solution using plant-derived materials. Environ. Sci. Pollut. Res. 2017, 24, 19159-19166. [CrossRef]

25. Mohan, D.; Sarswat, A.; Ok, Y.S.; Pittman, C.U., Jr. Organic and inorganic contaminants removal from water with biochar, a renewable, low cost and sustainable adsorbent-A critical review. Bioresour. Technol. 2014, 160, 191-202. [CrossRef]

26. Ferreira Mendes, K.; Nogueira de Sousa, R.; Takeshita, V.; Gimenes Alonso, F.; Justiniano Régo, A.P.; Tornisielo, V.L. Cow bone char as a sorbent to increase sorption and decrease mobility of hexazinone, metribuzin, and quinclorac in soil. Geoderma 2019, 343, 40-49. [CrossRef]

27. Loffredo, E.; Parlavecchia, M.; Perri, G.; Gattullo, R. Comparative assessment of metribuzin sorption efficiency of biochar, hydrochar and vermicompost. J. Environ. Sci. Health B 2019, 54, 728-735. [CrossRef] [PubMed]

28. Yu, J.; Zhu, Z.; Zhang, H.; Guanglan, D.; Qiu, Y.; Yin, D.; Wang, S. Hydrochars from pinewood for adsorption and nonradical catalysis of bisphenols. J. Hazard. Mat. 2020, 385, 121548. [CrossRef]

29. Altenburger, R.; Scholze, M.; Busch, W.; Escher, B.I.; Jakobs, G.; Krauss, M.; Krüger, J.; Neale, P.; Ait-Aissa, S.; Almeida, A.; et al. Mixture effects in samples of multiple contaminants-An inter-laboratory study with manifold bioassays. Environ. Int. 2018, 114, 95-106. [CrossRef]

30. PubChem Open Chemistry Database at the National Institutes of Health (NIH); U.S. National Library of Medicine. Available online: https:/ / pubchem.ncbi.nlm.nih.gov/compound/8814 (accessed on 20 July 2021).

31. Lagergren, S. Zur theorie der sogenannten adsorption gelöster stoffe, Kungliga Svenska Vetenskapsakademiens. Handlingar 1898, 24, 1-39. [CrossRef]

32. Kumar, K.V. Linear and non-linear regression analysis for the sorption kinetics of methylene blue onto activated carbon. J. Hazard. Mater. 2006, B137, 1538-1544. [CrossRef]

33. Ho, Y.S. Second-order kinetic model for the sorption of cadmium onto tree fern: A comparison of linear and non-linear methods. Water Res. 2006, 40, 119-125. [CrossRef]

34. Barriuso, E.; Laird, D.A.; Koskinen, W.C.; Dowdy, R.H. Atrazine desorption from smectites. Soil Sci. Soc. Am. J. 1994, 58, 1632-1638. [CrossRef]

35. Sicong Yao, S.; Fabbricino, M.; Race, M.; Ferraro, A.; Pontoni, L.; Aimone, O.; Chen, Y. Study of the digestate as an innovative and low-cost adsorbent for the removal of dyes in wastewater. Processes 2020, 8, 852. [CrossRef]

36. Essandoh, M.; Wolgemuth, D.; Pittman, C.U., Jr.; Mohan, D.; Mlsna, T. Adsorption of metribuzin from aqueous solution using magnetic and nonmagnetic sustainable low-cost biochar adsorbents. Environ. Sci. Pollut. Res. 2017, 24, 4577-4590. [CrossRef]

37. Zhao, J.; Zhou, D.; Zhang, J.; Li, F.; Chu, G.; Wu, M.; Pan, B.; Steinberg, C.E.W. The contrasting role of minerals in biochars in bisphenol A and sulfamethoxazole sorption. Chemosphere 2021, 264, 128490. [CrossRef]

38. Aly, Z.; Graulet, A.; Scales, N.; Hanley, T. Removal of aluminium from aqueous solutions using PAN-based adsorbents: Characterisation, kinetics, equilibrium and thermodynamic studies. Environ. Sci. Pollut. Res. 2014, 21, 3972-3986. [CrossRef] [PubMed]

39. Ho, Y.S.; Mckay, G. Pseudo-second order model for sorption processes. Process. Biochem. 1999, 34, 451-465. [CrossRef]

40. Giles, C.H.; MacEwan, T.H.; Nakhwa, S.N.; Smith, D. Studies in adsorption. Part XI. A system of classification of solution adsorption isotherms, and its use in diagnosis of adsorption mechanisms and in measurement of specific surface areas of solids. J. Chem. Soc. 1960, 111, 3973-3993. [CrossRef]

41. Prasannamedha, G.; Senthil Kumar, P.; Mehala, R.; Sharumitha, T.J.; Surendhar, D. Enhanced adsorptive removal of sulfamethoxazole from water using biochar derived from hydrothermal carbonization of sugarcane bagasse. J. Hazard. Mat. 2021, $407,124825$. [CrossRef] 
42. Loffredo, E.; Senesi, N. The role of humic substances in the fate of anthropogenic organic pollutants in soil with emphasis on endocrine disruptor compounds. In Soil and Water Pollution Monitoring, Protection and Remediation; NATO Science Series IV-Earth and Environmental Sciences; Springer International Publishing AG: Cham, Switzerland, 2006; Volume 69, pp. 69-92. [CrossRef]

43. Gaullier, C.; Dousset, S.; Billet, D.; Baran, N. Is pesticide sorption by constructed wetland sediments governed by water level and water dynamics? Environ. Sci. Pollut. Res. 2018, 25, 14324-14335. [CrossRef] [PubMed]

44. Ying, G.-G.; Kookana, R.S.; Dillon, P. Sorption and degradation of selected five endocrine disrupting chemicals in aquifer material. Water Res. 2003, 37, 3785-3791. [CrossRef] 